\title{
GHSR methylation-dependent expression of a variant ligand and receptor of the ghrelin system induces thymoma tumorigenesis
}

\author{
BILGUUN TEGSHEE ${ }^{1}$, KAZUYA KONDO ${ }^{1}$, SHIHO SOEJIMA ${ }^{1}$, KYOKA MUGURUMA $^{1}$, MITSUHIRO TSUBOI ${ }^{2}$, \\ KOICHIRO KAJIURA ${ }^{2}$, YUKIKIYO KAWAKAMI ${ }^{2}$, NAOYA KAWAKITA ${ }^{2}$, HIROAKI TOBA ${ }^{2}$, \\ MITSUTERU YOSHIDA ${ }^{2}$, HIROMITSU TAKIZAWA ${ }^{2}$ and AKIRA TANGOKU ${ }^{2}$ \\ ${ }^{1}$ Department of Oncological Medical Services, Graduate School of Biomedical Sciences, Tokushima University, \\ Tokushima, Tokushima 770-8509; ${ }^{2}$ Department of Thoracic, Endocrine Surgery and Oncology, \\ Graduate School of Biomedical Sciences, Tokushima University, Kuramoto-cho, Tokushima 770-8503, Japan
}

Received March 4, 2021; Accepted August 19, 2021

DOI: 10.3892/ol.2021.13054

\begin{abstract}
Our previous study reported that the DNA methylation of growth hormone secretagogue receptor $(G H S R)$ was significantly higher in thymoma or thymic carcinoma (TC) than in normal thymic tissue samples. Thymic epithelial tumors (TETs) with higher GHSR DNA methylation were associated with significantly worse prognosis than those with lower levels of DNA methylation. Diversified components of the ghrelin-GHSR axis may exert opposing effects in cancer progression, depending on the cancer type in question. However, the precise function of the axis remains unclear. In the present study, the mRNA expression of five key components of the ghrelin system [native ligand ghrelin, variant ligand In-1 ghrelin, native receptor GHSR1a, variant receptor GHSR1b and acylation enzyme ghrelin O-acyltransferase (GOAT)] were examined in 58 TET samples by reverse transcription-quantitative PCR, and protein expression of GHSR1a and GHSR $1 b$ was assessed in 20 TETs using immunohistochemistry. The results revealed that In-1 ghrelin, GHSR $1 b$ (variant forms) and GOAT were more strongly expressed in thymoma compared with thymic-adjacent tissue. By contrast, no significant differences were observed in the expression of ghrelin and GHSR1a (native forms) between thymoma and thymic tissue. The mRNA expression of In-1 ghrelin and GHSR $1 \mathrm{~b}$ (variant forms) was positively associated with GHSR methylation in thymoma tissue samples. However, a relationship was not found between ghrelin, GHSR1a or GOAT expression (native forms) and GHSR methylation in thymoma. Immunohistochemical analysis revealed that mRNA expression of GHSR1a and GHSR1b generally correlated with expression of the corresponding protein, and that the expression of GHSR1b was increased in advanced-stage TETs. These results
\end{abstract}

Correspondence to: Dr Kazuya Kondo, Department of Oncological Medical Services, Graduate School of Biomedical Sciences, Tokushima University, 3-18-15 Kuramoto, Tokushima, Tokushima 770-8509, Japan E-mail:kzykondo@tokushima-u.ac.jp

Key words: ghrelin, GHSR, In-1 ghrelin, thymoma, thymic carcinoma, thymic epithelial tumors indicate that the DNA methylation of GHSR is associated with a shift from native expression (ghrelin and GHSR1a) to variant expression (In-1 ghrelin and GHSR1b), which induces the tumorigenesis of thymoma, but not TC.

\section{Introduction}

TETs, including thymoma and thymic carcinoma (TC), are the primary neoplasms of epithelial cells in the thymic gland of the anterior mediastinum. Thymoma is a low-grade malignant tumor associated with myasthenia gravis and other autoimmune diseases, whereas TC is an aggressive tumor with no known molecular links to autoimmune diseases (1). The World Health Organization (WHO) histopathological classification system distinguishes thymoma from TC and neuroendocrine tumors of the thymus (NECTT), and divides thymoma into five categories (types $\mathrm{A}, \mathrm{AB}, \mathrm{B} 1, \mathrm{~B} 2$ and $\mathrm{B} 3$ ) based on the morphology of epithelial cells and the lymphocyte-to-epithelial cell ratio (2). To date, various staging systems have been proposed for TETs. The Masaoka-Koga classification is currently the most widely accepted clinical staging system, which is based on local invasion and tumor metastasis (3). The new TNM stage classification system, now in the 8th edition, can be used for all TETs, and considers not only tumor characteristics, but also lymph nodal and metastatic characteristics (4).

Treatment of TETs may involve surgery, radiation and/or chemotherapy, and optimal treatment depends on the clinical stage. The resectability of a tumor influences patient prognosis, and surgery remains the mainstay of treatment forTETs. Surgical resection and/or postoperative radiotherapy is appropriate for most patients with completely resected TETs. Multimodality therapy involving surgery, chemotherapy and radiotherapy appears to increase the rate of complete resection and survival in advanced TETs (5-7); one-third of patients that present with advanced-stage or relapsing tumors require administration of chemotherapy, and systemic review recommends that the most popular and active regimens are cisplatin-anthracycline and cisplatin-etoposide combinations $(8,9)$. However, metastatic and inoperable refractory/recurrent TETs, particularly TC, are associated with poor prognosis (10). The rarity of these tumors makes clinical trials difficult, and the development of novel 
drugs is slow (11). Thus, focusing on specific molecular alterations may provide a clearer understanding of TETs and aid the development of targeted therapies.

In the past decade, attempts have been made to characterize TETs at the molecular level, and the aberrant expression of EGFR (12), VEGF (13), insulin-like growth factor 1 receptor (14) and programmed cell death protein 1 /programmed cell death 1 ligand 1 (15) has been shown to contribute to the tumorigenesis of TETs. However, the rarity of these tumors hampers the development of targeted therapy (11). Only a few targeted drugs have progressed to phase-II trials, including mTOR (16) and KIT tyrosine kinase inhibitors (17). Therefore, the identification of novel biological targets is important for the introduction of molecular profiling-directed therapies in clinical practice (11).

Our previous study included the genome-wide screening of aberrantly-methylated $\mathrm{CpG}$ islands in thymoma and TC using the Infinium ${ }^{\circledR}$ Human Methylation 450K BeadChip (Illumina, Inc.), and identified $92 \mathrm{CpG}$ islands that were significantly hypermethylated in TC compared with thymoma. Furthermore, four cancer-related genes (GHSR, GNG4, HOXD9 and SALL3) were selected, for which promoter methylation was examined in 46 TETs and 20 paired thymic tissue sample using bisulfite pyrosequencing. The results revealed that promoter methylation of these genes was significantly higher in TC than in thymoma and normal thymic tissue. In addition, relapse-free survival (RFS) was significantly worse in tumors with higher DNA methylation than for those with lower DNA methylation levels in all TET samples (18).

GHSR is aberrantly hypermethylated in a number of cancer types (including lung, breast, prostate, pancreatic and colorectal cancer, as well as glioblastoma and B cell chronic lymphocytic leukemia), and its methylation levels may be used to discriminate between cancer and normal tissue (19). GHSR is a receptor of ghrelin that regulates functional processes, such as hormone secretion, the energy balance and gastric acid release (20). GHSR encodes a member of the $\mathrm{G}$ protein-coupled receptor family that has two known transcripts, native GHSR1a and variant GHSR1b. GHSR1a is the primary functional receptor for the endogenous ligand ghrelin. The splice variant GHSR1b is not activated by ghrelin or growth hormone secretagogues, and thus, it currently not known whether the receptor is functional (21). The splice variant of native ghrelin, In-1 ghrelin may be acylated by ghrelin-O-acyltransferase (GOAT) to facilitate binding with GHSR1a. Since it shares the initial 13 amino acids with native ghrelin, In-1 ghrelin may also activate GHSR1a (22).

The aim of the present study was to systematically investigate the presence of different components of the ghrelin system (native ghrelin, GOAT and GHSR1a) and splicing variants (In-1 ghrelin and GHSR1b) in thymoma and TC, in order to compare their expression with that in adjacent thymic samples and to validate the results at the protein level using immunohistochemistry (IHC). The association between the DNA methylation of GHSR and the mRNA expression of ghrelin-GHSR family members was also investigated.

\section{Materials and methods}

Patients and samples. The present study was conducted using a retrospective, observational design. In total, 58 TET tissue samples were obtained from patients with histologically confirmed TET who underwent surgery at Tokushima University Hospital (Tokushima, Japan) between January 1990 and January 2018 (median age, 62 years; mean age, 59.86 \pm 11.87 ; range, 28-84 years). In addition, 17 paired adjacent thymic tissue samples were obtained from the patients. The patient characteristics are displayed in Table SI. Tissue samples were snap-frozen and stored at $-80^{\circ} \mathrm{C}$ until the isolation of DNA and RNA. Tumor specimens were characterized using the Masaoka-Koga staging system (3) and WHO histological classification (23) (Tables SII and SIII). The present study was approved by the Ethics Committee of the University of Tokushima (Tokushima, Japan; approval no. 3759), and was conducted according to the Declaration of Helsinki. Written informed consent was obtained from all patients.

RNA extraction. RNA was extracted from frozen tissue using the RNeasy Mini kit (Qiagen $\mathrm{GmbH}$ ) according to the manufacturer's instructions. The quantity and purity of nucleic acid were assessed using a spectrophotometer (NanoDrop-1000; Thermo Fisher Scientific, Inc.) and diluted to $1.0 \mu \mathrm{g} / \mu \mathrm{l} ; 1 \mu \mathrm{l}$ RNA from each sample was used for reverse transcription.

Reverse transcription-quantitative $(R T-q) P C R$. Total RNA was reverse transcribed to cDNA using iScript Reverse Transcription Supermix for RT-qPCR (Bio-Rad Laboratories, Inc.), and qPCR was performed using Sso Advanced Universal SYBR-Green Supermix (Bio-rad Laboratories, Inc.) and the 96-well format Applied Biosystems 7500 Real-Time PCR System (Thermo Fisher Scientific, Inc.) according to the manufacturers' instructions. Temperature and duration of reverse transcription were as follows: Priming for $5 \mathrm{~min}$ at $25^{\circ} \mathrm{C}$, reverse transcription for $20 \mathrm{~min}$ at $46^{\circ} \mathrm{C}$, and inactivation for $1 \mathrm{~min}$ at $95^{\circ} \mathrm{C}$. The thermocycling condition used for qPCR consisted of an initial step at $95^{\circ} \mathrm{C}$ for $30 \mathrm{sec}$, followed by 40 cycles of denaturation $\left(95^{\circ} \mathrm{C}\right.$ for $\left.15 \mathrm{sec}\right)$ and annealing/extension $\left(60^{\circ} \mathrm{C}\right.$ for $1 \mathrm{~min})$. The sequences of the specific primers for ghrelin, In-1 ghrelin, GHSR1a, GHSR1b and GOAT were obtained from a previous study by Luque et al (24). The mRNA levels of $\beta$-actin were used as an internal control for normalization. All primer sequences for qPCR are shown in Table SIV. The relative mRNA expression levels were calculated using Human Thymus Total RNA (Takara Bio, Inc.) as a normal thymus control. Relative gene expression was calculated using the $2^{-\Delta \Delta \mathrm{Cq}}$ method (25).

IHC. Formalin-fixed paraffin-embedded (FFPE) sections (thickness, $3 \mu \mathrm{m}$ ) were stained using the Envision system (ChemMate Envision kit; Dako; Agilent Technologies, Inc.) according to the manufacturer's instructions. After dewaxing in xylene and rehydration in a descending ethanol series, antigen retrieval was performed by heating in Dako Real Target Retrieval Solution, pH 9 (Dako; Agilent Technologies, Inc.) at $>120^{\circ} \mathrm{C}$ using a pressure chamber (2100 Retriever; Aptum Biologics Ltd.) for $20 \mathrm{~min}$. Tissue samples were incubated overnight at $4{ }^{\circ} \mathrm{C}$ with the following primary antibodies: Rabbit Anti-GHS-R1A (1:500; cat. no. H-001-62; Phoenix Pharmaceuticals, Inc.) and Rabbit Anti-GHS-R1B (1:400; cat. no. H-001-61; Phoenix Pharmaceuticals, Inc.). The tissue samples were incubated with ready-to-use peroxidase 
labelled polymer secondary antibody (EnVision+ Dual Link System-HRP; cat. no. K4063; Dako; Agilent Technologies, Inc.) at room temperature for $1 \mathrm{~h}$. The proportion and intensity of GHSR1a and GHSR1b staining were scored independently by BT, KKo and SS. Staining intensity was scored as follows: Negative, 0; weak, 1; moderate, 2; and strong, 3. Proportion score was defined as follows: $\leq 30 \%$ positive cells, 0 ; $31-70 \%$ positive cells, 1 ; and $\geq 70 \%$ positive cells, 2 . The staining score was defined as the sum of the proportion and intensity scores, and a score $\geq 4$ indicated strong staining for the GHSR proteins.

Statistical analysis. Descriptive results are expressed as the mean \pm standard deviation. The Shapiro-Wilk test was applied to assess the normality of numerical datasets. When data were normally distributed, expression between the tumor tissues was assessed using an unpaired sample t-test, while differential expression between tumor tissues and adjacent thymic tissues was assessed using a paired sample t-test. Multiple comparisons were evaluated using one-way ANOVA followed by Dunnett's post hoc test. When data exhibited non-normal distribution, expression between the tumor tissues was assessed using the Mann-Whitney U test, and differential expression between tumor tissues and adjacent thymic tissues was assessed using the Wilcoxon signed-rank test. Multiple comparisons were assessed using the Kruskal-Wallis test followed by Dunn's post hoc test. Methylation-dependent expression analysis and gene expression correlation analysis were carried out using Pearson's correlation coefficient when datasets were normally distributed, while Spearman's rank correlation coefficient was applied for non-normally distributed datasets. Categorical data were assessed using Fisher's exact test. RFS analyses were performed using the Kaplan-Meier method and compared with the log-rank (Mantel-Cox) test. High- or low-expression groups were assigned based on median values. Statistical analyses were performed using GraphPad Prism 5.00 (GraphPad Software, Inc.) and SPSS 25.0 (IBM Corp), and $\mathrm{P}<0.05$ was considered to indicate a statistically significant difference.

\section{Results}

Patient characteristics. In total, 58 patients (25 male and 33 female; mean age $59.86 \pm 11.97$ years) diagnosed with TETs were included in the present study. Of these, 13 patients also had myasthenia gravis (Table SI). According to the WHO histological classification, 41 samples were thymoma, 13 were TC (including a single case of TC combined with type B2 thymoma) and 4 were NECTT. Tumor characteristics are displayed in Tables SII and SIII.

In all TET cases $(\mathrm{n}=58)$, the median follow-up time was 5.25 years (range, $0.36-22.41$ years); 2 patients died from their tumors, 1 from another disease and 1 from an unknown cause. Furthermore, 18 patients experienced recurrence: Pleural dissemination in 10, lung metastasis in 6, lymph node metastasis in 3 and multiple organ metastasis in 2 (Table SI). In thymoma cases $(n=41)$, the median follow-up time was 5.43 years (range, 0.75-22.41 years); 1 patient died from another disease and 1 from an unknown cause. In addition, 7 patients experienced recurrence: Pleural dissemination in 5 and lung metastasis in 2. Clinicopathological characteristics of the patients and corresponding DNA methylation, RNA expression, and protein expression levels are provided in Table SV.

Relative expression of ghrelin system components in TETs and paired thymic tissue samples. The mRNA expression of ghrelin system components in thymoma (Fig. 1A) and TC (Fig. 1B) tissue was compared with that in matched thymic tissue samples. The RT-qPCR results revealed that expression of the splicing variant ligand In-1 ghrelin and variant receptor GHSR1b were significantly higher in thymoma than in adjacent thymic tissue samples $(\mathrm{P}=0.0059$ and $\mathrm{P}=0.0488$, respectively; Wilcoxon signed-rank test). By contrast, no significant differences were observed in the expression of the native ligand ghrelin and native receptor GHSR1a between thymoma and adjacent thymic tissue. The expression of the ghrelin-activating enzyme GOAT was significantly higher in thymoma tissue than in adjacent thymic tissue samples $(\mathrm{P}=0.0371$; Wilcoxon signed-rank test). On the other hand, no significant changes were noted in the expression of five components of the ghrelin-GHSR family in TC + NECTT (Fig. 1B). Overall, the data indicate that In-1 ghrelin, GHSR $1 b$ and GOAT expression were significantly higher in thymoma tissues than in thymic-adjacent tissues.

Expression of ghrelin system components in the thymus, thymoma and TC + NECTT. The differential quantitative expression of ghrelin family transcripts in the thymus, thymoma and TC + NECTT is displayed in Fig. 2. The median expression rates of In-1 ghrelin in the thymus, thymomas and TC + NECTT were $0.120,0.3750$ and 0.260 , respectively. The median expression rate of the variant ligand In-1 ghrelin was significantly higher in thymoma than in the thymus ( $\mathrm{P}=0.0170$; Kruskal-Wallis test). The corresponding expression rates of the variant receptor GHSR $1 \mathrm{~b}$ in the normal thymus, thymomas, and TC + NECTT were 3.020, 11.93 and 16.67 , respectively, and the median expression rate of GHSR $1 \mathrm{~b}$ was slightly higher in thymoma than in the thymus $(\mathrm{P}=0.0547$; Kruskal-Wallis test). Furthermore, no significant differences were observed in the expression of the native ligand ghrelin, native receptor GHSR1a and GOAT. Therefore, expression analysis of ghrelin system components in TETs indicated that In-1 ghrelin was upregulated in thymoma tissues, but not in TC. Also, there was a tendency for GHSR $1 b$ to be expressed at a higher level in thymoma.

Expression of ghrelin system components at different tumor stages. The expression of each of the five transcripts was investigated at different tumor stages using the Masaoka-Koga staging system. The stages were stratified into two distinct groups [early (stage I+II) and advanced (stage III+IV)], and expression was compared. The results indicated that the median expression levels of In-1 ghrelin in the early and advanced stages of TET were, respectively: i) 0.3650 and 0.3150 for In-1 ghrelin; ii) 3.045 and 4.370 for ghrelin; iii) 3.445 and 3.510 for GHSR1a; iv) 13.37 and 14.36 for GHSR1b; and v) 1.320 and 1.095 for GOAT. These differences were not statistically significant (Fig. S1). Collectively, the data indicate that the expression of ghrelin system constituents did not significantly differ between TET stages. 
A

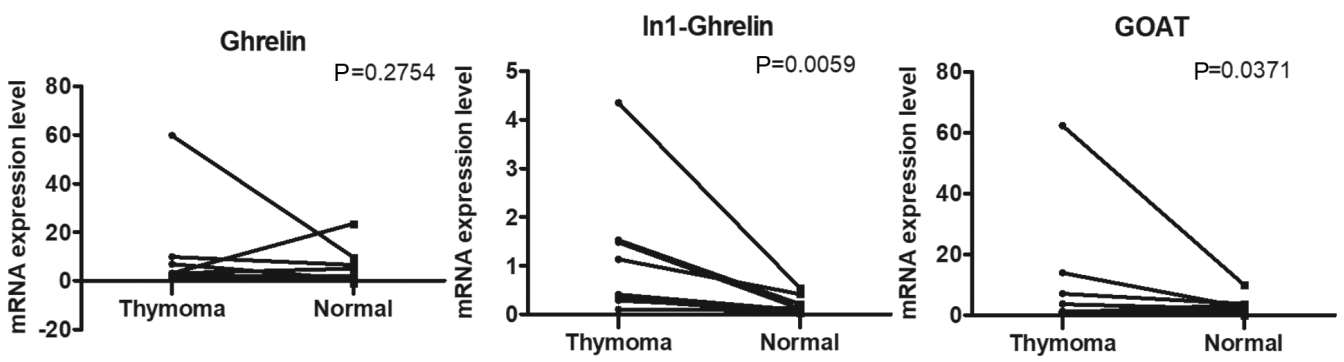

GHSR1a
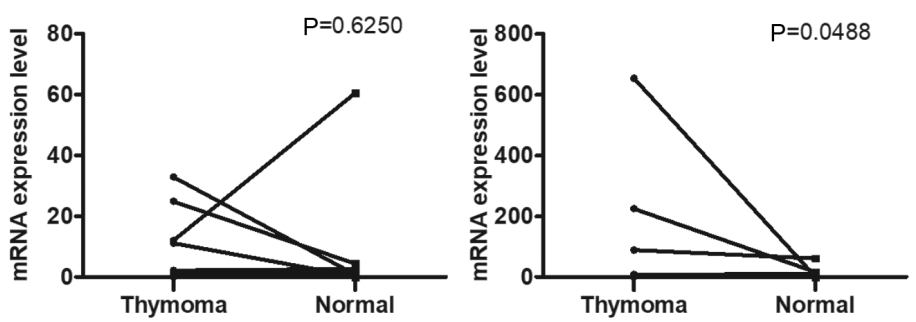

B

Ghrelin

In1-Ghrelin

GOAT
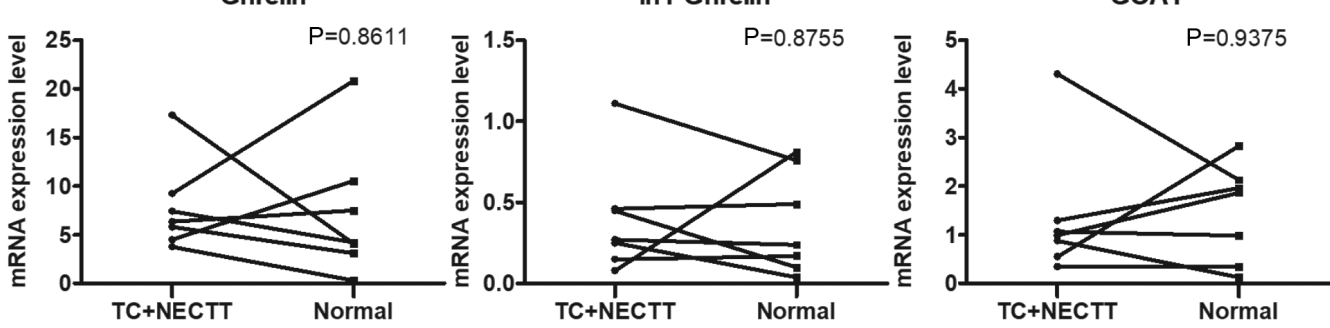

GHSR1a
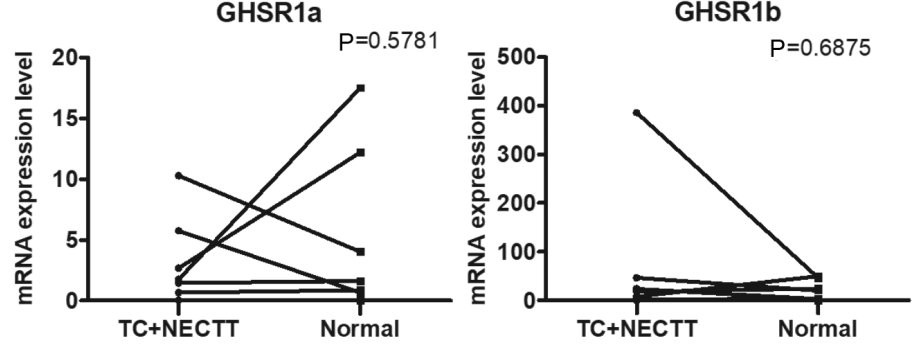

Figure 1. Relative expression of ghrelin family components. (A) Quantitative expression of ghrelin family components in thymoma and paired adjacent thymic tissue. $n=10$ /group. (B) Quantitative expression of ghrelin family components in TC + NECTT and paired adjacent thymic tissue. $n=7 /$ group. P-values were generated using the Wilcoxon rank-sum test. GHSR, growth hormone secretagogue receptor; GOAT, ghrelin O-acyltransferase; TC, thymic carcinoma; NECTT, neuroendocrine tumors of the thymus.

RFS analysis of patients with TETs and different $m R N A$ levels of ghrelin, In-1 ghrelin, GHSRIa, GHSRIb and GOAT. The levels of ghrelin, In-1 ghrelin, GHSR1a, GHSR1b and GOAT were divided into high- or low-expression groups based on their median values, and RFS analysis was conducted. Although no significant differences were observed between the groups, there was a tendency for tumors with slightly higher expression levels of the variant ligand In-1 ghrelin, variant receptor GHSR 1b and GOAT to be associated with poor prognosis in patients with TETs (Fig. S2).

Comparative DNA methylation and gene expression analysis. Methylation-dependent expression analysis was performed to clarify whether the expression of ghrelin family components was associated with the methylation of GHSR. Our previous study reported the hypermethylation of GHSR in thymoma and TC tissue relative to adjacent thymic tissue samples (18). The present results showed that mRNA expression of the variant ligand In-1 ghrelin and variant receptor GHSR $1 \mathrm{~b}$ was positively associated with GHSR methylation ( $\varrho=0.4007$ and $\varrho=0.4259$, respectively; Spearman's rank correlation coefficient) in thymoma tissue, whereas that of native ghrelin, the native receptor GHSR1a and GOAT was not (Fig. S3A and Table I). Furthermore, the expression of ghrelin, In-1 ghrelin, GHSR1a, GHSR1b and GOAT was not associated with GHSR methylation in TC + NECTT tissue (Fig. S3B and Table I). 
Table I. Association between GHSR methylation and expression levels of ghrelin system components in thymic epithelial tumors.

\begin{tabular}{|c|c|c|c|c|}
\hline \multirow{2}{*}{$\begin{array}{l}\text { Tumor } \\
\text { Gene }\end{array}$} & \multicolumn{2}{|c|}{ Thymoma } & \multicolumn{2}{|c|}{$\mathrm{TC}+\mathrm{NECTT}$} \\
\hline & P-value & @ value & P-value & @ value \\
\hline Ghrelin & 0.5292 & -0.1321 & 0.9044 & -0.03396 \\
\hline In1-Ghrelin & $0.0472^{\mathrm{a}}$ & 0.4007 & 0.4664 & 0.2038 \\
\hline GHSR1a & 0.5007 & 0.1412 & 0.8168 & -0.06821 \\
\hline GHSR1b & $0.0380^{\mathrm{a}}$ & 0.4259 & 0.7806 & 0.07864 \\
\hline Ghrelin O-acyltransferase & 0.2880 & 0.2212 & 0.5933 & 0.1501 \\
\hline
\end{tabular}

${ }^{\mathrm{a}} \mathrm{P}<0.05$; Spearman's rank correlation coefficient. GHSR, growth hormone secretagogue receptor; TC, thymic carcinoma; NECTT, neuroendocrine tumor of the thymus.

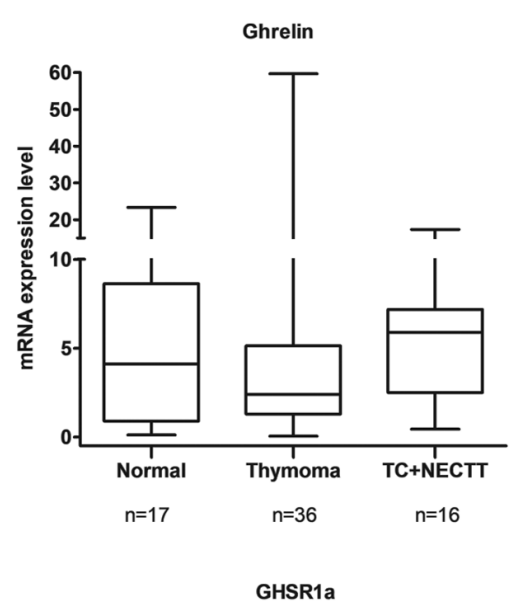

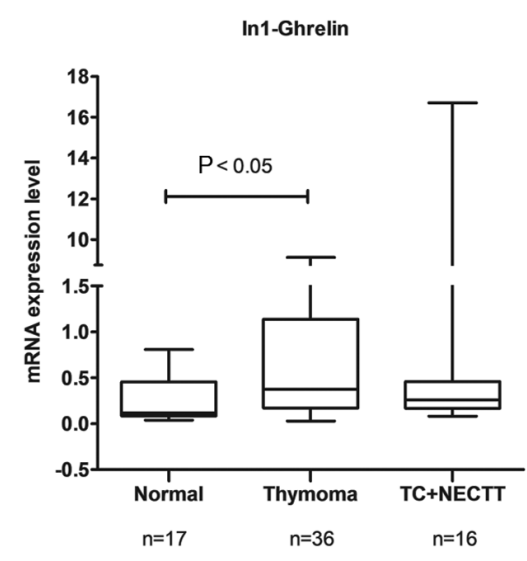

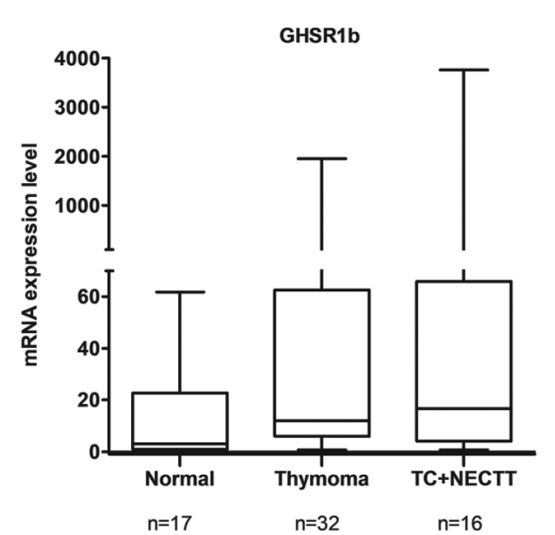

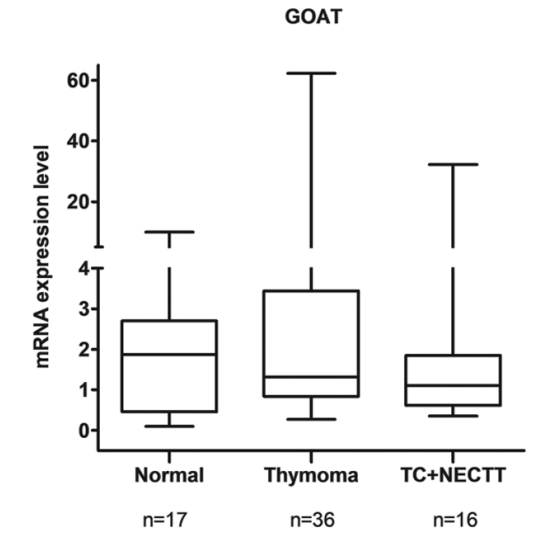

Figure 2. Expression of ghrelin family transcripts in thymic, thymoma and TC + NECTT tissue. The expression levels of ghrelin family transcripts are shown as boxplots. P-value was generated using the Kruskal-Wallis test. GHSR, growth hormone secretagogue receptor; GOAT, ghrelin O-acyltransferase; TC, thymic carcinoma; NECTT, neuroendocrine tumors of the thymus.

Overall, these data indicate that the expression of variant ligand In-1 ghrelin and variant receptor GHSR $1 \mathrm{~b}$ is dependent on GHSR methylation in thymoma tissues.

Correlation analysis of gene expression levels. The relationships among the quantitative mRNA expression levels of each of the five transcripts of the ghrelin system (ghrelin, In-1 ghrelin, GHSR1a, GHSR1b and GOAT) were subsequently determined using Spearman's rank correlation coefficient. The results revealed a positive correlation between In-1 ghrelin/GOAT $(\varrho=0.6232)$ in thymoma tissue. Similarly, correlations were observed between GHSR1b/GHSR1a as well as GHSR1a/GOAT, with $\varrho=0.5158$ and $\varrho=0.3944$, respectively (Fig. S4 and Table IIA). In TC + NECTT tissue samples, positive correlations were noted between In-1 ghrelin/GOAT, GOAT/GHSR1b and GHSR1b/GHSR1a $(\varrho=0.6824, \varrho=0.5676$ and $\varrho=0.6571$, respectively) (Fig. S5; Table IIB).

GHSR $1 a$ and GHSRIb protein expression analysis. GHSR1a and GHSR1b protein expression was identified in 20 TET tissue samples (including 14 thymoma and 6 TC tissue samples) and 3 thymic tissue samples. The staining of both proteins was cytoplasmic. Fig. 3A-a and B-a shows GHSR1a and GHSR1b staining, respectively, in the cytoplasm of epithelial cells but not lymphocytes in the normal thymus. 
Table II. Correlation analysis of the expression levels of ghrelin system components, in thymoma, TC and NECTT.

A, Thymoma

\begin{tabular}{|c|c|c|c|c|c|}
\hline Transcript & Ghrelin & In1-ghrelin & GOAT & GHSR1a & GHSR 1b \\
\hline Ghrelin & & -0.2146 & -0.2576 & -0.03045 & -0.07823 \\
\hline In1-Ghrelin & & & $0.6232^{\mathrm{c}}$ & 0.2270 & 0.2518 \\
\hline GOAT & & & & $0.3944^{\mathrm{a}}$ & 0.2051 \\
\hline GHSR1a & & & & & $0.5158^{b}$ \\
\hline GHSR1b & & & & & \\
\hline
\end{tabular}

$\mathrm{B}, \mathrm{TC}+\mathrm{NECTT}$

\begin{tabular}{|c|c|c|c|c|c|}
\hline Transcript & Ghrelin & In1-ghrelin & GOAT & GHSR1a & GHSR 1b \\
\hline Ghrelin & & 0.3353 & 0.09706 & -0.2143 & -0.04118 \\
\hline In1-Ghrelin & & & $0.6824^{\mathrm{b}}$ & -0.07143 & 0.3765 \\
\hline GOAT & & & & 0.1786 & $0.5676^{\mathrm{a}}$ \\
\hline GHSR1a & & & & & $0.6571^{b}$ \\
\hline GHSR1b & & & & & \\
\hline
\end{tabular}

Results are shown as $Q$ values. ${ }^{\mathrm{a}} \mathrm{P}<0.05,{ }^{\mathrm{b}} \mathrm{P}<0.01$ and ${ }^{\mathrm{c}} \mathrm{P}<0.001$; Spearman's rank correlation coefficient. TC, thymic carcinoma; NECTT, neuroendocrine tumor of the thymus; GOAT, ghrelin O-acyltransferase; GHSR, growth hormone secretagogue receptor.

A

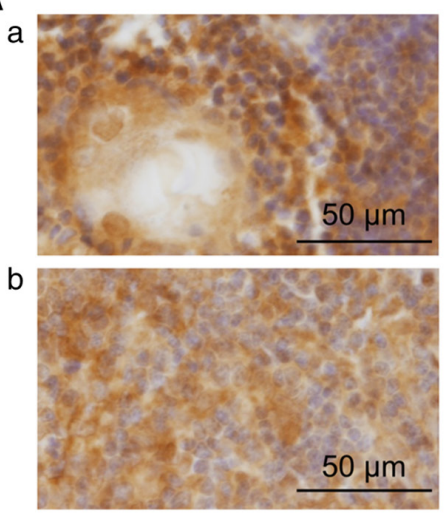

C

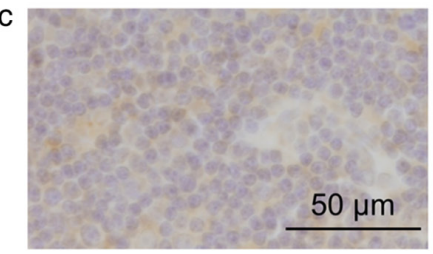

d

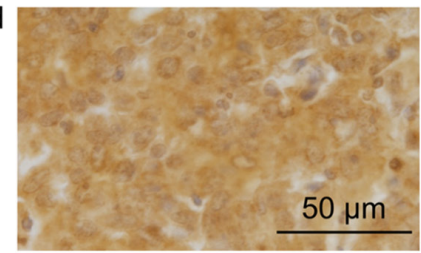

B

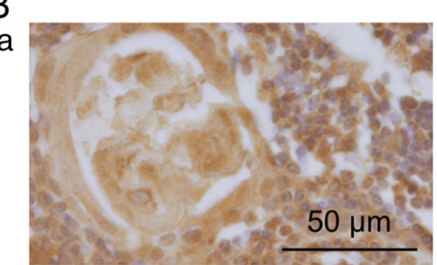

b

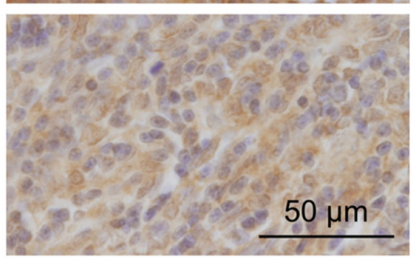

c

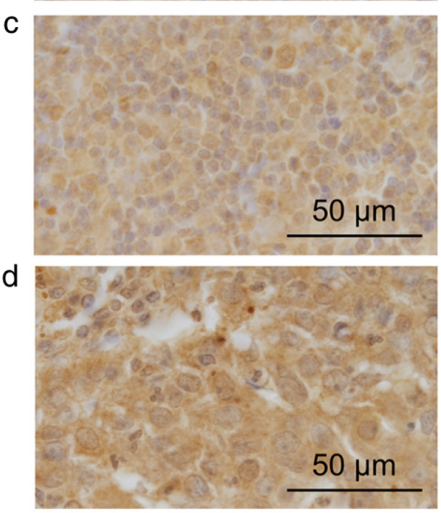

C
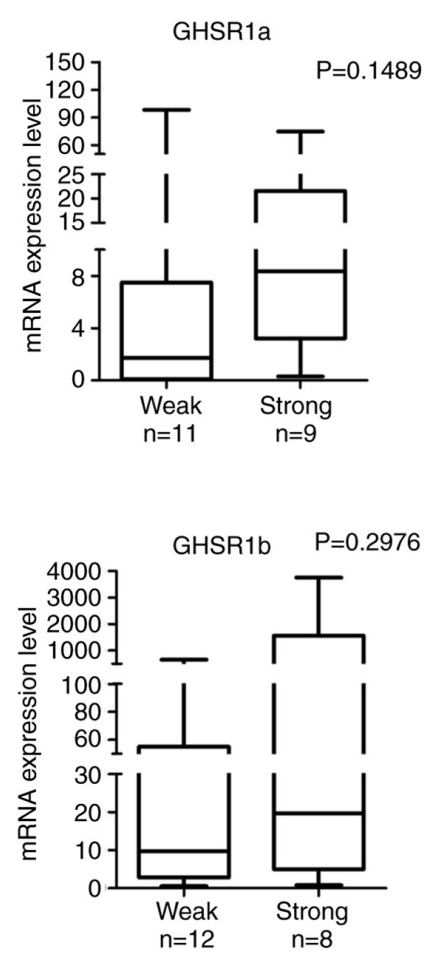

Figure 3. Protein expression analysis. (A) Representative images of GHSR1a protein expression. (a) Thymic tissue: Dense aggregates of lymphocytes in the cortical area were not stained; epithelial cells of medullary area were stained. (b) Type AB thymoma: Cytoplasm of tumor cells was strongly stained, and lymphocytes were not stained (intensity score, 3; proportion score, 2). (c) Type B2 thymoma: Cytoplasm of the tumor cells was not stained (intensity score, 1; proportion score, 1). (d) TC: Cytoplasm of the tumor cells was strongly stained (intensity score, 3; proportion score, 2). (B) Representative images of GHSR1b protein expression. (a) Medullary area of thymus: Lymphocytes in the medullary area were not stained, epithelial cells were stained. (b) Type AB thymoma: Cytoplasm of the tumor cells was weakly stained, and lymphocytes were not stained. (intensity score, 2; proportion score, 1). (c) Type B2 thymoma: Cytoplasm of the tumor cells was strongly stained (intensity score, 3; proportion score, 1). (d) TC: Cytoplasm of the tumor cells was strongly stained (intensity score, 3; proportion score, 2). (C) Association between GHSR protein expression and corresponding mRNA expression. Analyses were performed using the Mann-Whitney U test. GHSR, growth hormone secretagogue receptor; TC, thymic carcinoma. 
Table III. Association between GHSR1a and GHSR1b immunoreactivity and clinicopathological characteristics in patients with thymic epithelial tumors.

\begin{tabular}{|c|c|c|c|c|c|c|}
\hline \multirow[b]{2}{*}{ Clinicopathological characteristics } & \multicolumn{3}{|c|}{ GHSR 1a immunoreactivity $(\mathrm{n}=20)$} & \multicolumn{3}{|c|}{ GHSR1b immunoreactivity $(n=20)$} \\
\hline & Weak $(n=11)$ & Strong $(\mathrm{n}=9)$ & P-value & Weak $(n=12)$ & Strong $(\mathrm{n}=8)$ & P-value \\
\hline Sex, female/male & $8 / 3$ & $6 / 3$ & 0.769 & $11 / 1$ & $3 / 5$ & 0.018 \\
\hline Mean age $\pm \mathrm{SD}$, years & $56.5 \pm 9.48$ & $61 \pm 13.04$ & 0.178 & $7 / 5$ & $3 / 5$ & 0.650 \\
\hline $\begin{array}{l}\text { Masaoka-Koga staging system, } \\
\text { stages I and II/III and IV }\end{array}$ & $10 / 1$ & $6 / 3$ & 0.285 & $11 / 1$ & $5 / 3$ & 0.255 \\
\hline $\begin{array}{l}\text { WHO histological classification, } \\
\text { thymoma/thymic carcinoma }\end{array}$ & $9 / 2$ & $5 / 4$ & 0.336 & $11 / 1$ & $3 / 5$ & $0.018^{\mathrm{a}}$ \\
\hline Mean GHSR 1a mRNA expression \pm SD & $1.71 \pm 29.2$ & $8.35 \pm 23.76$ & 0.1489 & NA & NA & NA \\
\hline Mean GHSR1b mRNA expression \pm SD & NA & NA & NA & $9.71 \pm 184.5$ & $19.61 \pm 1381.5$ & 0.2976 \\
\hline Myasthenia gravis, positive/negative & $7 / 4$ & $7 / 2$ & 0.642 & $7 / 5$ & $7 / 1$ & 0.325 \\
\hline
\end{tabular}

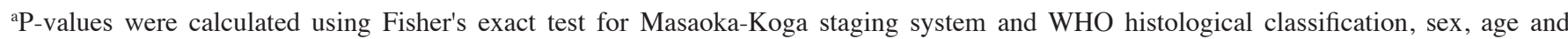
myasthenia gravis status. Mann-Whitney U test was used for GHSR1a and GHSR1b mRNA expression analysis. GHSR, growth hormone secretagogue receptor; WHO, World Health Organization; NA, not applicable.

Fig. 3A-b and B-b shows strong staining of GHSR1a and moderate staining of GHSR $1 \mathrm{~b}$, respectively, in type $A B$ thymoma. Fig. 3A-c and B-c shows weak staining of GHSR1a and strong staining of GHSR1b, respectively, in the type B2 thymoma. Fig. 3A-d and B-d shows strong staining of GHSR1a and GHSR1b, respectively, in TC. The tissue samples were grouped into weakly- and strongly-stained groups by their protein immunoreactivity, and the mRNA expression levels were compared. The mRNA expression levels of both GHSR1a and GHSR1b were higher in the strongly-stained group (mean GHSR1a, 8.35 \pm 23.76 ; mean GHSR1b, 19.61 \pm 1381.5 ) than in the weakly-stained group (mean GHSR1a, 1.71 \pm 29.2 ; mean GHSR1b, 9.71 \pm 184.5 ) (Fig. 3C and Table III). Furthermore, the relationship between the expression of GHSR1a and GHSR1b, and clinical findings (sex, age, tumor stage, pathology type and myasthenia gravis), was assessed. Table III shows that variant GHSR1b protein was higher in TC $(\mathrm{P}=0.018$; Fisher's exact test) and in men ( $\mathrm{P}=0.018$; Fisher's exact test). GHSR1a protein expression was not correlated with any of the assessed clinical findings. In addition, RFS analysis indicated that high expression of GHSR1b was not associated with prognosis $(\mathrm{P}=0.0624$; Fig. S6).

\section{Discussion}

Since the discovery of canonical ghrelin as an intrinsic ligand for GHSR, research has been conducted to elucidate its functions and pathophysiological roles. Though, the local expression of ghrelin and GHSR has been examined in different types of tumor tissue, the role of ghrelin as a proliferative or inhibitory factor in cancers remains controversial (26-31). Ghrelin has been shown to promote the proliferation of normal cell lines, though its function in cancer cell lines is still being debated. In in vitro studies, the ghrelin-GHSR axis promoted cancer cell migration and metastasis through several different downstream pathways (32-35). Diversified components of the ghrelin-GHSR axis might show opposing effects in cancer progression depending on the pathophysiological nature of the cancer type.

The current study aimed to comprehensively elucidate the role of ghrelin components (the native ligand ghrelin, native receptor GHRS1a, splicing variant ligand In-1 Ghrelin, variant receptor GHSR1b and key enzyme GOAT) in TETs. The results demonstrated that the variant ligand In-1 ghrelin and variant receptor GHSR $1 b$ were significantly upregulated in thymoma tissue, and no significant differences were observed in the expression of native receptor ghrelin and native receptor GHSR1a between thymoma and adjacent thymic tissue. On the other hand, in TC + NECTT, no significant differences were noted in the expression of ghrelin system components between tumor tissue and matched thymic tissue samples. Supporting evidence prior to the present study indicated that splicing variant In-1 ghrelin was significantly upregulated in all types of pituitary adenoma tissue and gastroenteropancreatic neuroendocrine tumors $(36,24)$. Likewise, upregulation of In-1 ghrelin in prostate and breast cancer was associated with the increased aggressiveness of the disease (37-39). GHSR1b was also found to be upregulated in hormone-related tumors, such as colorectal cancer, breast cancer, adrenocortical tumors and lung carcinoids (34,40-42). Accumulating evidence shows that In-1 ghrelin and GHSR $1 b$ play as oncogenic role in hormone-related tumors. Thymoma is a low-grade malignant tumor of the thymic epithelium with immature $\mathrm{T}$ cell migration associated with autoimmune diseases. However, TC is a malignant tumor with evidently atypical cells of an invasive nature without immature $\mathrm{T}$ cell migration and autoimmune disease $(1,6)$. Thymoma, but not TC, is a functioning tumor (6). In the present study, the variant ligand In-1 ghrelin and variant receptor GHSR $1 b$ were upregulated in thymoma, but not in TC tissue, which suggests that a switch in expression to the variant ligand and receptor from the native ligand and receptor of the ghrelin system contributes to the tumorigenesis of thymoma, but not TC.

In the present study, the co-expression of GHSR1a and GHSR1b was observed in thymoma and TC tissue samples. 
The upregulated co-expression of GHSR1a and GHSR1b was detected in growth hormone-secreting pituitary adenomas and adrenocorticotrophic hormone pituitary adenomas. By contrast, the expression of both receptors was significantly downregulated in non-functioning pituitary adenomas (36). In a human erythroleukemic cell line (HEL), the upregulation of GHSR1b was shown to stimulate cellular proliferation via an autocrine pathway (43). Until recently, GHSR1b was considered a non-functional orphan receptor due to the truncation process during alternative splicing, where it loses its ability to bind with its ligand ghrelin. Subsequent studies revealed that overexpression of GHSR1b attenuated GHSR constitutive signaling by heterodimerizing with GHSR1a (44). In non-small cell lung cancer, GHSR1b was found to heterodimerize with Neurotensin Receptor 1, which also belongs to the G-protein coupled receptor superfamily, and to exert growth-promoting effects by modulating the transcription of downstream target genes (45).

In the present study, although the result was not significant, there was a tendency towards higher expression of variant ligand In-1 ghrelin, variant receptor GHSR1b and the acylation enzyme GOAT in association with worse prognosis in patients with TET than those with lower expression levels. Rincón-Fernández et al (39) reported that the high expression of In-1 ghrelin in breast cancer samples was correlated with shorter RFS. Therefore, it may be hypothesized that the expression of In-1 ghrelin and GHSR1b could be used as a prognostic tool in thymoma. To confirm the mRNA expression results of ghrelin, In-1 ghrelin, GHSR1a and GHSR1b, the protein expression of these components in TETs and the thymus was assessed using IHC. Although commercially-available antibodies against GHSR1a and GHSR1b were used (which can discriminate between each protein), distinct antibodies against ghrelin and In-1 ghrelin could not be found. However, the mRNA expression levels of GHSR1a and GHSR1b were higher in the strongly-stained group than in the weakly-stained group. These results confirmed that mRNA expression of GHSR1a and GHSR 1b was roughly correlated with protein expression. Variant GHSR1b protein expression was higher in TC and in male patients. Thus the mRNA and protein expression of GHSR1b may promote the malignant behavior of the tumor.

GOAT is a key enzyme for the acylation of ghrelin (22). The present study revealed that the expression of GOAT was significantly upregulated in thymoma, but not in TC + NECTT tissue samples and a strong positive correlation was observed between GOAT and In-1 ghrelin expression in both thymoma and $\mathrm{TC}+$ NECTT tissue samples. However, the expression of GOAT did not correlate with that of native ghrelin. Similarly, GOAT was upregulated in NET and breast cancer tissue, and its expression was associated with that of In-1 ghrelin. Previous studies have reported increases in GOAT expression and its plasma levels in patients with prostate cancer, which was correlated with tumor aggressiveness $(38,46,47)$. Therefore, GOAT may act as a modulator of the elevated expression of In-1 ghrelin in thymoma.

Epigenetic abnormalities, such as aberrant promoter hypermethylation, associated with the functional disruption of genes, are found in all types of tumor (48). Due to the tumor-initiating role of this epigenetic dysregulation, methylation markers may be preferable for diagnosing tumors at the earliest stage (49). Hypermethylation of GHSR has been observed in numerous different tumor types, and is attracting interest as a pan-cancer marker in clinical practice, with promising sensitivity and specificity (19,50-54). Our previous research demonstrated that GHSR was significantly hypermethylated in thymoma and TC + NECTT tissue compared with adjacent-healthy thymic tissue samples (18). A previous study by Coppedè et al (55) examined the methylation rate of $\mathrm{CpG}$ islands of 152-bp located in the promoter/first exon region of GHSR in 65 surgically-resected myasthenia gravis-positive thymoma cases, and 43 adjacent thymic tissue samples, using the methylation-specific high-resolution melting (MS-HRM) method. The study showed that GHSR hypermethylation was observed in 18 thymomas (28\%) compared with the healthy thymus (mean, 5.1 vs. $0.2 \%$ ), and concluded that GHSR methylation was not a pan-cancer marker. This result is in contrast to a previous study by Kishibuchi et al (18), which examined the CpG sites found downstream of the transcriptional start site of GHSR. The result showed that all thymoma tissue samples were methylated, and that methylation level was significantly higher than that in the adjacent thymic tissue samples, irrespective of myasthenia gravis status. The results of both aforementioned studies cannot be easily compared due to the differences in methylation analysis methodology (pyrosequencing vs. MS-HRM). Taking this into account, we support the theory that GHSR hypermethylation is the epigenetic driver to different types of malignancies, and a promising candidate marker for pan-cancer detection.

The present study showed a positive correlation between the methylation of GHSR and the expression of variant ligand In-1 ghrelin and variant receptor GHSR1b in thymoma, but not in TC tissue samples. Therefore, the DNA methylation of GHSR may be associated with a shift from native expression (ghrelin and GHSR1a) to variant expression (In-1 ghrelin and GHSR1b) in thymoma.

There were some limitations to the present study, which need to be addressed. TC and NECT case numbers were lower (13 for TC and 4 for NECTT) than those with thymoma because these tumors are so rare. Due to the limited number of TET samples collected at Tokushima University, the overall sample size could not be increased. Thymoma can be divided into 5 types (types A, AB, B1, B2 and B3) based on the morphology of epithelial cells and the lymphocyte-to-epithelial cell ratio, and the ratio of lymphocytes to tumor cells is high in $A B, B 1$ and B2 thymoma (2). Since separate tumor cells could not be separated from lymphocytes prior to RNA extraction, the presence of lymphocytes in resected $\mathrm{AB}, \mathrm{B} 1$ and $\mathrm{B} 2$ thymomas may have influenced the mRNA expression rate. Thymoma is a low-grade malignancy; 58 patients with TET were followed up for 5.25 years (0.36-22.41 years), some of whom died; therefore, overall survival analysis could not be performed.

In conclusion, our previous studies revealed that GHSR was significantly hypermethylated in both thymoma and TC + NECTT tissue samples. To elucidate the role of the ghrelin-GHSR axis in TETs, the expression of five different components of the ghrelin system was systematically analyzed in tumor and normal tissue samples in the present study. The variant ligand In-1 ghrelin, variant receptor GHSR1b, and acylation enzyme GOAT were found to be upregulated in thymoma, but not in TC. Furthermore, the mRNA expression of the variant ligand In-1 ghrelin and variant receptor GHSR1b was positively associated with the DNA methylation of GHSR in thymoma tissue. Therefore, the DNA methylation of GHSR may be associated with a shift from 
native expression (ghrelin and GHSR1a) to variant expression (In-ghrelin and GHSR1b). Moreover, the slightly stronger expression of In-1 ghrelin, GHSR1b and GOAT was associated with a worse prognosis in patients with TET than those with weaker expression. The aberrant DNA methylation of the receptor and strong expression of the variant ligand and receptor may be related to the aggressive behavior of thymoma.

\section{Acknowledgements}

Not applicable.

\section{Funding}

The present study was supported in part by Grants-in-Aid for Scientific Research (grant no. 20K09178) from the Ministry of Education, Culture, Sports, Science and Technology, Japan.

\section{Availability of data and materials}

The datasets used and/or analyzed during the present study are available from the corresponding author upon reasonable request.

\section{Authors' contributions}

BT, KKo, HTa and AT conceived and designed the study. BT, KKo, SS and KM performed all experiments and data curation, and drafted the manuscript. MT and KKa analyzed and interpretated the curated data. BT, KKo, SS, YK and NK analyzed and interpreted patient gene expression data. BT, KKo, SS, HTo and MY performed the immunohistochemical staining and interpreted the association between the clinical data and immunoreactivity. All authors have read and approved the final manuscript. BT and KKo confirm the authenticity of all the raw data.

\section{Ethics approval and consent to participate}

The present study was performed in accordance with the principles outlined in the Declaration of Helsinki. Following the approval of all aspects of the present study by the local Ethics Committee of Tokushima University Hospital (approval no. 3759), formal written consent was obtained from all patients.

\section{Patient consent for publication}

Not applicable.

\section{Competing interests}

The authors declare that they have no competing interests.

\section{References}

1. Tateo V, Manuzzi L, De Giglio A, Parisi C, Lamberti G, Campana D, Pantaleo MA: Immunobiology of thymic epithelial tumors: Implications for immunotherapy with immune checkpoint inhibitors. Int J Mol Sci 21: 9056, 2020.

2. Travis WD, Brambilla E, Nicholson AG, Yatabe Y, Austin JH, Beasley MB, Chirieac LR, Dacic S, Duhig E, et al: The 2015 World Health Organization Classification of Lung Tumors: Impact of genetic, clinical and radiologic advances since the 2004 classification. J Thorac Oncol 10: 1243-1260, 2015.
3. Detterbeck FC, Nicholson AG, Kondo K, Van Schil P and Moran C: The Masaoka-Koga stage classification for thymic malignancies: clarification and definition of terms. J Thorac Oncol: Cancer 6: S1710-1716, 2011.

4. Lababede $\mathrm{O}$ and Meziane MA: The eighth edition of TNM staging of lung cancer: Reference chart and diagrams. Oncologist 23: 844-848,2018.

5. Kondo K: Therapy for thymic epithelial tumors. Gen Thorac Cardiovasc Surg 62: 468-474, 2014.

6. Shimosato Y, Mukai K and Matsuno Y: Tumors of the mediastinum. In: AFIP Atlas of Tumor Pathology, Series 4. Armed Forces Institute of Pathology, Washington, DC, 2010.

7. Kondo K and Monden Y: Therapy for thymic epithelial tumors: A clinical study of 1,320 patients from Japan. Ann Thorac Surg 76: $878885,2003$.

8. Berghmans T, Durieux V, Holbrechts S, Jungels C, Lafitte JJ, Meert AP, Moretti L, Ocak S, Roelandts M, et al: Systemic treatments for thymoma and thymic carcinoma: A systematic review. Lung Cancer 126: 25-31, 2018.

9. Girard N, Ruffini E, Marx A, Faivre-Finn C and Peters S: Thymic epithelial tumours: ESMO Clinical Practice Guidelines for diagnosis, treatment and follow-up. Ann Oncol 26: v40-v55, 2015.

10. Scorsetti M, Leo F, Trama A, D'Angelillo R, Serpico D, Macerelli M, Zucali P, Gatta G and Garassino MC: Thymoma and thymic carcinomas. Crit Rev Oncol Hematol 99: 332-350, 2016.

11. Kelly RJ, Petrini I, Rajan A, Wang Y and Giaccone G: Thymic malignancies: from clinical management to targeted therapies. J Clin Oncol 29: 4820-4827, 2011.

12. Suzuki E, Sasaki H, Kawano O, Endo K, Haneda H, Yukiue H, Kobayashi Y, Yano M and Fujii Y: Expression and mutation statuses of epidermal growth factor receptor in thymic epithelial tumors. Jpn J Clin Oncol 36: 351-356, 2006.

13. Cimpean AM, Raica M, Encica S, Cornea R and Bocan V: Immunohistochemical expression of vascular endothelial growth factor $\mathrm{A}$ (VEGF), and its receptors (VEGFR1, 2) in normal and pathologic conditions of the human thymus. Ann Anat 190: 238-245, 2008.

14. Girard N, Teruya-Feldstein J, Payabyab EC, Riely GJ, Rusch VW, Kris MG and Zakowski MF: Insulin-like growth factor-1 receptor expression in thymic malignancies. J Thorac Oncol 5: 1439-1446, 2010.

15. Weissferdt A, Fujimoto J, Kalhor N, Rodriguez J, Bassett R, Wistuba II and Moran CA: Expression of PD-1 and PD-L1 in thymic epithelial neoplasms. Mod Pathol 30: 826-833, 2017.

16. Zucali PA, De Pas T, Palmieri G, Favaretto A, Chella A, Tiseo M, Caruso M, Simonelli M, Perrino M, et al: Phase II study of everolimus in patients with thymoma and thymic carcinoma previously treated with cisplatin-based chemotherapy. J Clin Oncol 36: 342-349, 2018.

17. Thomas A, Rajan A, Berman A, Tomita Y, Brzezniak C, Lee MJ, Lee S, Ling A, Spittler AJ, et al: Sunitinib in patients with chemotherapy-refractory thymoma and thymic carcinoma: an open-label phase 2 trial. Lancet Oncol 16: 177-186, 2015.

18. KishibuchiR,KondoK,SoejimaS,Tsuboi M,KajiuraK,KawakamiY, Kawakita N, Sawada T, Toba H, et al: DNA methylation of GHSR, GNG4, HOXD9 and SALL3 is a common epigenetic alteration in thymic carcinoma. Int J Oncol 56: 315-326, 2020.

19. Moskalev EA, Jandaghi P, Fallah M, Manoochehri M, Botla SK, Kolychev OV, Nikitin EA, Bubnov VV, von Knebel Doeberitz M, et al: GHSR DNA hypermethylation is a common epigenetic alteration of high diagnostic value in a broad spectrum of cancers. Oncotarget 6: 4418-4427, 2015.

20. Kojima M and Kangawa K: Ghrelin: Structure and Function. Physiol Rev 85: 495-522, 2005.

21. Howard AD, Feighner SD, Cully DF, Arena JP, Liberator PA, Rosenblum CI, Hamelin M, Hreniuk DL, Palyha OC, et al: A receptor in pituitary and hypothalamus that functions in growth hormone release. Science 273: 974-977, 1996.

22. Seim I, Herington AC and Chopin LK: New insights into the molecular complexity of the ghrelin gene locus. Cytokine Growth Factor Rev 20: 297-304, 2009.

23. Travis WD, Brambilla E, Burke AP, Marx A and Nicholson AG: introduction to the 2015 World Health Organization classification of tumors of the lung, pleura, thymus, and heart. J Thorac Oncol 10: 1240-1242, 2015.

24. Luque RM, Sampedro-Nuñez M, Gahete MD, Ramos-Levi A, Ibáñez-Costa A, Rivero-Cortés E, Serrano-Somavilla A, Adrados M, Culler MD, et al: In1-ghrelin, a splice variant of ghrelin gene, is associated with the evolution and aggressiveness of human neuroendocrine tumors: Evidence from clinical, cellular and molecular parameters. Oncotarget 6: 19619-19633, 2015.

25. Livak KJ and Schmittgen TD: Analysis of relative gene expression data using real-time quantitative PCR and the $2^{-\Delta \Delta C T}$ method. Methods 25: 402-408, 2001. 
26. Lin T-C and Hsiao M: Ghrelin and cancer progression. Biochim Biophys Acta Rev Cancer 1868: 51-57, 2017.

27. Volante M, Allia E, Fulcheri E, Cassoni P, Ghigo E, Muccioli G and Papotti M: Ghrelin in fetal thyroid and follicular tumors and cell lines: expression and effects on tumor growth. Am J Pathol 162: 645-654, 2003.

28. Cassoni P, Papotti M, Ghè C, Catapano F, Sapino A, Graziani A, Deghenghi R, Reissmann T, Ghigo E, et al: Identification, characterization, and biological activity of specific receptors for natural (ghrelin) and synthetic growth hormone secretagogues and analogs in human breast carcinomas and cell lines. J Clin Endocrinol Metab 86: 1738-1745, 2001.

29. Bai RX, Wang WP, Zhao PW and Li CB: Ghrelin attenuates the growth of HO-8910 ovarian cancer cells through the ERK pathway. Braz J Med Biol Res 49: e5043, 2016.

30. Díaz-Lezama N, Hernández-Elvira M, Sandoval A, Monroy A Felix R and Monjaraz E: Ghrelin inhibits proliferation and increases T-type $\mathrm{Ca}^{2+}$ channel expression in $\mathrm{PC}-3$ human prostate carcinoma cells. Biochem Biophys Res Commun 403: 24-29, 2010

31. Cassoni P, Allia E, Marrocco T, Ghè C, Ghigo E, Muccioli G and Papotti M: Ghrelin and cortistatin in lung cancer: Expression of peptides and related receptors in human primary tumors and in vitro effect on the H345 small cell carcinoma cell line. J Endocrinol Invest 29: 781-790, 2006.

32. Lin TC, Liu YP, Chan YC, Su CY, Lin YF, Hsu SL, Yang CS and Hsiao M: Ghrelin promotes renal cell carcinoma metastasis via Snail activation and is associated with poor prognosis J Pathol 237: 50-61, 2015.

33. Dixit VD, Weeraratna AT, Yang H, Bertak D, Cooper-Jenkins A, Riggins GJ, Eberhart CG and Taub DD: Ghrelin and the growth hormone secretagogue receptor constitute a novel autocrine pathway in astrocytoma motility. J Biol Chem 281: 16681-16690, 2006.

34. Waseem T, Javaid ur R, Ahmad F, Azam M and Qureshi MA: Role of ghrelin axis in colorectal cancer: A novel association. Peptides 29: 1369-1376, 2008.

35. Duxbury MS, Waseem T, Ito H, Robinson MK, Zinner MJ, Ashley SW and Whang EE: Ghrelin promotes pancreatic adenocarcinoma cellular proliferation and invasiveness. Biochem Biophys Res Commun 309: 464-468, 2003.

36. Ibáñez-Costa A, Gahete MD, Rivero-Cortés E, RincónFernández D, Nelson R, Beltrán M, de la Riva A, Japón MA Venegas-Moreno E, et al: In1-ghrelin splicing variant is overexpressed in pituitary adenomas and increases their aggressive features. Sci Rep 5: 8714, 2015.

37. Hormaechea-Agulla D, Gahete MD, Jiménez-Vacas JM, Gómez-Gómez E, Ibáñez-Costa A, L-López F, Rivero-Cortés E, Sarmento-Cabral A, Valero-Rosa J, et al: The oncogenic role of the In1-ghrelin splicing variant in prostate cancer aggressiveness. Mol Cancer 16: 146, 2017.

38. Gahete MD, Córdoba-Chacón J, Hergueta-Redondo M, Martínez-Fuentes AJ, Kineman RD, Moreno-Bueno G, Luque RM and Castaño JP: A Novel Human Ghrelin Variant (In1-Ghrelin) and Ghrelin-O-Acyltransferase Are Overexpressed in Breast Cancer: Potential Pathophysiological Relevance. PLoS One 6: e23302, 2011.

39. Rincón-Fernández D, Culler MD, Tsomaia N, Moreno-Bueno G, Luque RM, Gahete MD and Castaño JP: In1-ghrelin splicing variant is associated with reduced disease-free survival of breast cancer patients and increases malignancy of breast cancer cells lines. Carcinogenesis 39: 447-457, 2018

40. Jeffery PL, Murray RE, Yeh AH, McNamara JF, Duncan RP, Francis GD, Herington AC, Chopin LK: Expression and function of the ghrelin axis, including a novel preproghrelin isoform, in human breast cancer tissues and cell lines. Endocr Relat Cancer 12: 839-850, 2005.

41. Barzon L, Pacenti M, Masi G, Stefani AL, Fincati K and Palù G: Loss of growth hormone secretagogue receptor la and overexpression of type $1 \mathrm{~b}$ receptor transcripts in human adrenocortical tumors. Oncology 68: 414-421, 2005.
42. Herrera-Martínez AD, Gahete MD, Sánchez-Sánchez R, Salas RO, Serrano-Blanch R, Salvatierra Á, Hofland LJ, Luque RM, Gálvez-Moreno MA, et al: The components of somatostatin and ghrelin systems are altered in neuroendocrine lung carcinoids and associated to clinical-histological features. Lung Cancer. The components of somatostatin and ghrelin systems are altered in neuroendocrine lung carcinoids and associated to clinical-histological features. Lung Cancer 109: 128-136, 2017.

43. De Vriese C, Grégoire Fo, De Neef P, Robberecht P and Delporte C: Ghrelin is produced by the human erythroleukemic HEL cell line and involved in an autocrine pathway leading to cell proliferation. Endocrinology 146: 1514-1522, 2005.

44. Leung PK, Chow KB, Lau PN, Chu KM, Chan CB, Cheng CH and Wise $\mathrm{H}$ : The truncated ghrelin receptor polypeptide (GHS-R1b) acts as a dominant-negative mutant of the ghrelin receptor. Cell Signal 19: 1011-1022, 2007.

45. Takahashi K, Furukawa C, Takano A, Ishikawa N, Kato T, Hayama S, Suzuki C, Yasui W, Inai K, et al: The neuromedin $\mathrm{U}$-growth hormone secretagogue receptor $1 \mathrm{~b} /$ neurotensin receptor 1 oncogenic signaling pathway as a therapeutic target for lung cancer. Cancer Res 66: 9408-9419, 2006.

46. Gómez-Gómez E, Jiménez-Vacas JM, Carrasco-Valiente J, Herrero-Aguayo V, Blanca-Pedregosa AM, León-González AJ, Valero-Rosa J, Fernández-Rueda JL, González-Serrano T, et al: Plasma ghrelin O-acyltransferase (GOAT) enzyme levels: A novel non-invasive diagnosis tool for patients with significant prostate cancer. J Cell Mol Med 22: 5688-5697, 2018.

47. Herrera-Martínez AD, Gahete MD, Sánchez-Sánchez R, Alors-Perez E, Pedraza-Arevalo S, Serrano-Blanch R, Martínez-Fuentes AJ, Gálvez-Moreno MA, Castaño JP, et al: Ghrelin-O-Acyltransferase (GOAT) enzyme as a novel potential biomarker in gastroenteropancreatic neuroendocrine tumors. Clin Transl Gastroenterol 9: 196, 2018

48. Jones PA and Baylin SB: The fundamental role of epigenetic events in cancer. Nat Rev Genet 3: 415-428, 2002.

49. Brena RM, Plass C and Costello JF: Mining methylation for early detection of common cancers. PLoS Med 3: e479, 2006.

50. Ordway JM, Budiman MA, Korshunova Y, Maloney RK, Bedell JA, Citek RW, Bacher B, Peterson S, Rohlfing T, et al: Identification of Novel High-Frequency DNA Methylation Changes in Breast Cancer. PLoS One 2: e1314, 2007.

51. Daugaard I, Dominguez D, Kjeldsen TE, Kristensen LS, Hager H, Wojdacz TK and Hansen LL: Identification and validation of candidate epigenetic biomarkers in lung adenocarcinoma. Sci Rep 6: 35807, 2016.

52. Nakagawa T, Matsusaka K, Misawa K, Ota S, Takane K, Fukuyo M, Rahmutulla B, Shinohara KI, Kunii N, et al: Frequent promoter hypermethylation associated with human papillomavirus infection in pharyngeal cancer. Cancer Lett 407: 21-31, 2017.

53. Verlaat W, Snijders PJF, Novianti PW, Wilting SM, De Strooper LM, Trooskens G, Vandersmissen J, Van Criekinge W, Wisman GB, et al: Genome-wide DNA methylation profiling reveals methylation markers associated with $3 \mathrm{q}$ gain for detection of cervical precancer and cancer. Clin Cancer Res: 23: 3813-3822, 2017.

54. Coppede F, Stoccoro A, Lazzarotti A, Spisni R and Migliore L: Investigation of GHSR and GHRL methylation in colorectal cancer. Epigenomics 10: 1525-1539, 2018.

55. Coppedè F, Stoccoro A, Nicolì V, Gallo R, De Rosa A, Guida M, Maestri M, Lucchi M, Ricciardi R, et al: Investigation of GHSR methylation levels in thymomas from patients with Myasthenia Gravis. Gene 752: 144774, 2020.

This work is licensed under a Creative Commons Attribution 4.0 International (CC BY-NC 4.0) License 